\title{
Asymmetric Organocatalysis: A New Stream in Organic Synthesis
}

\author{
Peter I. Dalko
}

\section{1 Introduction}

In common with metal complexes and enzymes, small organic molecules may promote chemical transformations. Organocatalysis provides a means of accelerating chemical reactions with a substoichiometric amount of organic molecules, which do not contain a metal element $[1,2]$.

Despite this rich historical past, the use of small organic molecules as chiral catalysts has only recently been recognized as a valuable addition and/or alternative to existing, well-established, often metal-based methodologies in asymmetric synthesis. Driven both by distinguished scientific interest, which usually accompanies emerging fields, and the recognition of the huge potential of this new area, organocatalysis has finally developed into a practical synthetic paradigm [3-15]. The question must be asked, however, as to why it has taken so long for chemists to appreciate and exploit the potential of small organic molecules as chiral catalysts. Why was not the imagination of the vast majority of the chemical community captured by the perspectives of asymmetric organocatalysis, when metal complex-derived catalysis underwent steady development for enantioselective reactions?

Principally, asymmetric organocatalytic reactions were, for a long time, considered to be inefficient and limited in scope. In parallel, organometallic catalysts provided a flexible ground for all types of reaction, and thus received disproportionate emphasis. Although today the vast majority of reactions in asymmetric catalysis continue to rely on organometallic complexes, this picture is changing, and organic catalysis is becoming an increasingly important segment of organic chemistry, offering a number of advantages over metal-based and bioorganic methods.

Today, reactions can be performed under an aerobic atmosphere, with wet solvents; indeed, the presence of water is often beneficial to the rate and selectivity of the reaction. The operational simplicity and ready availability of these mostly inexpensive bench-stable catalysts - which are incomparably more robust than 
enzymes or other bioorganic catalysts - makes organocatalysis an attractive method for the synthesis of complex structures. Unlike any earlier developed system, organocatalytic reactions provide a rich platform for multicomponent, tandem, or domino-type multistep reactions [16], allowing increases in the structural complexity of products in a highly stereocontrolled manner. In addition, fewer toxicity issues are often associated with organocatalysis, although this applies only when utilizing the more notorious metals. It should also be pointed out that little is currently known regarding the toxicity of many organic catalysts; moreover, there is no risk of metal leakage, and no expensive recovery process is required for waste treatment. Nowadays, increasing numbers of industrial applications are based on asymmetric organocatalytic reactions, and the environmentally friendly, "green" aspect of this chemistry - coupled with the sustainability of the catalysts - is considered widely for replacing standard, metal-based reactions $[17,18]$.

\section{2}

\section{Historical Background}

The history of organocatalytic reactions has a rich past, there being evidence that such catalysis has in the past played a determinant role in the formation of prebiotic key building blocks such as sugars. In this way, the reactions have led to the introduction and widespread use of homochirality in the living word [19]. Enantiomerically enriched amino acids such as L-alanine and L-isovaline, which may be present in up to $15 \%$ enantiomeric excess (ee) in carbonaceous meteorites, were able to catalyze the aldol-type dimerization of glycolaldehyde, as well as the reaction between glycolaldehyde and formaldehyde producing sugar derivatives. For example, Pizzarello and Weber were able to demonstrate that L-isovaline, which was found in the Murchison meteorite, promotes the self-aldol reaction of glycolaldehyde in water, generating aldol products such as L-threose and D-erythrose with up to $10.7 \pm 1.2 \%$ and $4.8 \pm 0.9 \mathrm{ee}$, respectively [19]. Proline, the most efficient natural amino acid catalyst in aldol-type condensations is scarcely present in meteorites. Asymmetric photolysis in interstellar clouds may produce optically active proline, however, indicating that proline may also have been transported to Earth [20]. The formation of sugars under prebiotic conditions was amplified in a number of elegant de-novo constructions of complex, differentiated carbohydrates by chemical synthesis [21]. It is likely, therefore, that these aldol products were the precursor of complex molecules such as RNA and DNA. Prebiotic RNA most likely played a central role in orchestrating a number of key biochemical transformations necessary for life, in which sugars served as chiral templates [22]. For example, it is considered, that amino acid homochirality in proteins was determined during asymmetric aminoacylation, which is the first step in protein synthesis and thus was critical for the transition from the putative RNA world to the theater of proteins [23]. According to this concept, the se- 
lectivity (L or D) of amino acids was determined in large part by the preestablished homochirality of RNA.

Organic molecules have been used as catalysts from the early age of synthetic chemistry. Indeed, the discovery of the first organocatalytic reaction is attributed to J. von Liebig, who found - accidentally - that dicyan is transformed into oxamide in the presence of an aqueous solution of acetaldehyde (Scheme 1.1). Subsequently, this efficient reaction found industrial application by forming the basis of the Degussa oxamide synthesis.

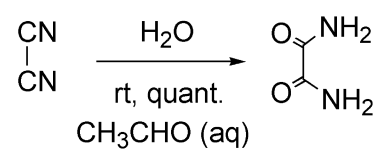

Scheme 1.1 von Liebig's oxamide synthesis.

Undoubtedly, the discovery of enzymes and enzyme functions had an important impact on the development of asymmetric catalytic reactions. The first asymmetric reaction - a decarboxylative kinetic resolution - was discovered by Pasteur [24], who observed that the organism Penicillium glauca destroyed more rapidly one of the enantiomers $(d)$ from a racemic solution of ammonium tartrate. Asymmetric decarboxylation reactions were re-examined under non-enzymatic conditions by Georg Breding during the early 1900s. Breding, who had a remarkably wide interdisciplinary interest, was motivated to find the chemical origin of enzyme activity observed in living organisms. In his early experiments he showed enantiomerical enrichment in the thermal decarboxylation of optically active camphorcarboxylic acid in $d$ and $l$ limonenes, respectively [25]. As an extension of this work he studied this decarboxylation reaction in the presence of chiral alkaloids, such as nicotine or quinidine, and established the basic kinetic equations of this kinetic resolution [26]. The first asymmetric $\mathrm{C}-\mathrm{C}$ bond forming reaction is attributed also to his name. This milestone achievement is related to Rosenthaler's work, who was able to prepare mandelonitrile by the addition of HCN to benzaldehyde in the presence of an isolated enzyme, emulsin [27]. Breding was also able to perform this reaction in the presence of alkaloids as catalysts, such as the pseudoenantiomeric quinine and quinidine (Scheme 1.2) [28]. It should be noted

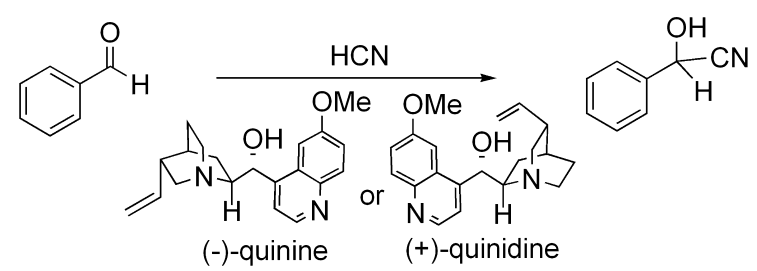

Scheme 1.2 
that, although these studies were considered as conceptually groundbreaking, the enantioselectivity of the reaction was less than $10 \%$.

Although catalytic transformations gained increasing importance after the First World War, asymmetric reactions were considered at the time to be an academic curiosity. Of note, the determination of enantioselectivity was hampered by a lack of methods to achieve not only efficient purification but also reliable analyses. Hence, the presence of a chiral impurity - which often arose from the catalyst spoiled the determination of the correct, optical rotation-based ee-values.

Nitrogen-containing natural products such as alkaloids (in particular strychnine, brucine and cinchona alkaloids) and amino acids (including short oligopeptides) were among the first organic catalysts to be tested. The acylative kinetic resolution of racemic secondary alcohols was initiated during the late 1920s by Vavon and Peignier in France [29], and, independently, also by Wegler in Germany [30]. These authors showed that brucine and strychnine were able to induce enantiomeric enrichment either in the esterification of meso dicarboxylic acids or in the kinetic resolution of secondary alcohols, albeit with low ee-values.

Also, Wolfgang Langenbeck's contribution should be remembered, who developed reactions, which were promoted by simple amino acids, or, by small oligopeptides [31]. A major part of these studies were dedicated to reactions which emulated enzyme functions by using simple amino acids or small peptides. Not surprisingly, enamine-type reactions were among the first to be discovered. This finding was initiated by the studies of Dakin who, in 1909, noted that in a Knoevenagel-type condensation between aldehydes and carboxylic acids or esters with active methylene groups, the amine catalysts could be mediated by amino acids [32]. The reaction was extended to aldol and related transformations, and studied systematically from the early 1930s onwards with notable success, essentially with non-asymmetric systems.

The reinvestigation of Breding's asymmetric cyanohydrin synthesis by Prelog during the mid-1950s [33] undoubtedly promoted the concept of asymmetric synthesis, and led the way to more efficient reactions. The advent of synthetically useful levels of enantioselectivity can be dated to the late 1950s, when Pracejus reported that methyl phenyl ketene could be converted to (-)- $\alpha$-phenyl methylpropionate in $74 \%$ ee by using $O$-acetylquinine as catalyst [34].

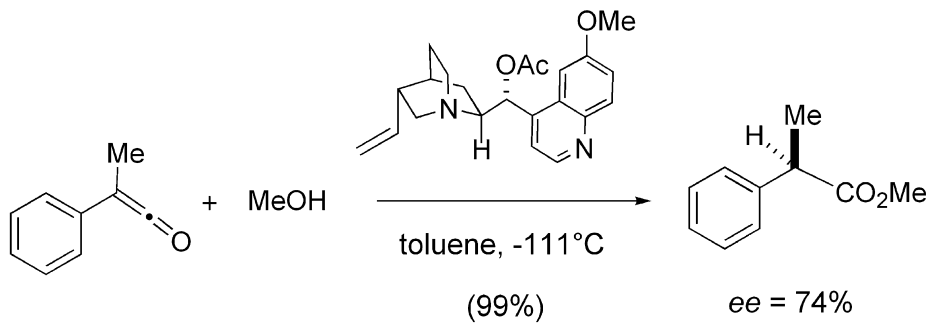

Scheme 1.3 Pracejus' enantioselective ester synthesis from phenyl methyl ketene. 
This quite impressive result inspired the reinvestigation of other possible reaction manifolds for the cinchona catalyst system. Bergson and Långström reported the first Michael addition of $\beta$-keto esters to acrolein using 2-(hydroxymethyl)quinuclidine as catalyst [35]. Although they never determined the enantiomeric excess, these authors noted the optical activity of their products. Wynberg and co-workers carried out extensive studies of the use of cinchona alkaloids as chiral Lewis-base/nucleophilic catalysts [36], and showed this class of alkaloid to be a versatile catalyst, promoting a variety of 1,2- and 1,4-additions of a wide range of nucleophiles to carbonyl compounds. Noteworthy, in these early studies it was often observed that natural cinchona alkaloids were superior, in terms of both catalytic activity and selectivity, to modified cinchona alkaloids derived from modification of the C-9 hydroxyl group. In order to rationalize this phenomenon, Wynberg proposed that the natural cinchona alkaloids were bifunctional catalysts utilizing both the tertiary amine and hydroxyl group to activate and orient the nucleophile and electrophile, respectively, thus achieving optimum asymmetric catalysis [36].

Another key event in the history of organocatalytic reaction was the discovery of efficient L-proline-mediated asymmetric Robinson annulation reported during the early 1970s. The so-called Hajos-Parrish-Eder-Sauer-Wiechert reaction (an intramolecular aldol reaction) allowed access to some of the key intermediates for the synthesis of natural products (Scheme 1.4) [37, 38], and offered a practical and enantioselective route to the Wieland-Miescher ketone [39]. It is pertinent to note, that this chemistry is rooted in the early studies of Langenbeck and in the extensive investigations work of Stork and co-workers on enamine chemistry [40].

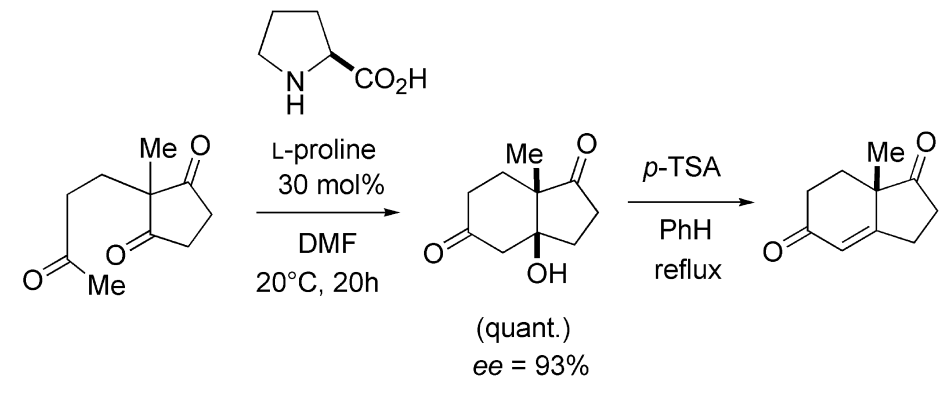

Scheme 1.4 The L-proline-mediated Robinson annulation.

This L-proline-mediated annulation received a considerable synthetic and mechanistic interest [41]. It was demonstrated that other amino acids, such as $(R)$-phenylalanine, could replace in some cases advantageously the L-proline [42]. Earlier applications in total syntheses appeared, however, as singular events, as in Woodward's synthesis of erythromycin (Scheme 1.5) [27]. Remarkably, in this synthesis a racemic keto aldehyde 5 could be used for aldolization with D-proline 
<smiles>C[C@H](COCc1ccccc1)CS[C@@H]1CC(=O)CCS1</smiles>

$1: 1$ mixture of diastereomers<smiles>O=C[C@H]1CCCN1</smiles>

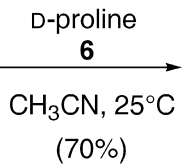

$(70 \%)$<smiles>O=C1CCS[C@H]2SC[C@H](COCc3ccccc3)C(O)[C@]12O</smiles>

$e e=36 \%$

Scheme 1.5 The D-proline-mediated intramolecular aldol reaction in Woodward's erythromycin synthesis.

(6) as catalyst. All of the chiral centers of the erythronolide backbone are derived either directly or indirectly from this rather poor reaction, which was only of $36 \%$ ee. However, an optically pure downstream product of 7 was separated by simple recrystallization, which made the process eminently practical (Scheme 1.5).

The late 1970s and early 1980s marked a clear turning point, with the advent not only of more general efficient asymmetric organocatalysts but also of organocatalytic reactions. During this period a number of reactions which proceeded via ion-pairing mechanisms (i.e., similar of that noted with the propos of cinchona alkaloids) were uncovered. In addition, chiral diketopiperazines were developed by Inoue as chiral Brønsted acids for the asymmetric hydrocyanation reactions [43], this reaction paving the way for the efficient hydrocyanation reactions of aldimines developed some years later by the groups of Lipton and Jacobsen [44, 45]. The advent of efficient phase-transfer reactions dates back to the mid-1980s, when researchers at Merck reported that substituted 2-phenyl-1-indanone systems could be alkylated with remarkably high enantioselectivity (up to 94\%) in the presence of catalytic amounts of substituted $\mathrm{N}$-benzylcinchoninium halides (50\% $\mathrm{NaOH} /$ toluene) [46]. Mention should be made here of the chiral aminemediated cycloaddition reactions, which were pioneered by Kagan [47], as well as the earliest examples of the enantioselective oxidation of chalcones using polyamino- or resin-bonded polyamino acid under tri- and biphasic conditions, the so-called Julià reaction [48]. Reinvestigation of the Hajos-Parrish-EderSauer-Wiechert reaction by List and Barbas during the late 1990s also opened an avenue for a number of related transformations such as the enantioselective intermolecular cross-aldol reactions, as well as Mannich, Michael and DielsAlder-type transformations, and the application of these transformations in multistep (domino) reactions [3, 16].

\section{3}

\section{Catalysts}

As metals easily form Lewis acids, organic catalysts are more prone to form heteroatom-centered Lewis bases. Among these catalysts, the N-and P-based 
forms are the most studied, with amine catalysts being more easily available than their phosphorus-containing counterparts, due mainly to the natural abundance. There is no natural P-containing chiral substrate for catalytic use, and consequently all of these catalysts are man-made [49]. One particular advantage of phosphorus-based catalysts is their ability to act as both a nucleophilic and stereogenic reaction center. The difference in Brønsted basicity of the phosphorus atom compared to the amine function may also be advantageous in avoiding basemediated secondary reactions.

It should be noted that not only the Lewis base but also typical Lewis acid roles can be emulated by organocatalytic systems. The proton is arguably the most common Lewis acid found in Nature, and these exist in two forms classified by the nature of the hydrogen bond: polar covalent $(\mathrm{RX}-\mathrm{H})$ and polar ionic $\left(\mathrm{RX}^{+} \mathrm{H} \cdots \mathrm{Y}^{-}\right)$. In the former case, in asymmetric transformations the chiral information is dictated by the chiral anion, whilst in the latter case the anion is nonchiral and the enantioselectivity is introduced by a chiral ligand (usually an amine base), which complexates the proton. This activation is discussed more extensively in Chapter 7.

Another class of activation is related to the particular reactivity of the nitrogen, and is referred to as aminocatalysis. Amine catalysts may give rise either to enamine or iminium intermediates [50]; the former activation results in an increased electron density at the reaction center(s), while the latter activation corresponds to a decrease in electron density at the reaction center(s). One peculiarity of this type of chemistry is the facile equilibrium between these two electron-rich and electron-deficient states (i.e., the acid-base form) of the same center. It is easy to conceive this equilibrium simply by considering protonation-deprotonation, which on the one hand may activate the reagent and, on the other hand may contribute to the kinetic lability of the ligand. The peculiarity of this activation is the fact that, due to this equilibrium process, the same center may act as either a Lewis acid or Lewis base, depending on the reaction conditions (Scheme 1.6). While both intermediates are formed in the same mixture, the relative concentrations of these structures is determined by the reaction conditions, leading to chemical transformations which follow entirely different mechanistic pathways and usually result in different products. More importantly, the same catalyst may promote complementary nucleophile/electrophile activation (i.e., promoting reactions via
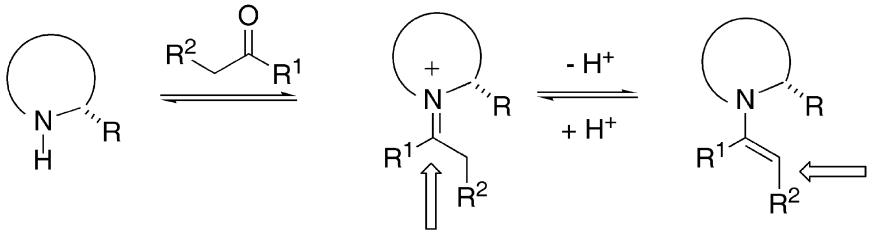

decreased electron density on $\mathrm{C}$ more electrophilic increased electron density on $\mathrm{C}$ more nucleophilic

Scheme 1.6 
enamine and iminium intermediates, respectively) in the same reaction pot, in a domino sequence [51].

Another particular area of organic catalysis is that of Lewis acid activation by a Lewis base. This catalysis represents a powerful means of modulating the electron density of weakly electron-withdrawing centers. Such an interaction operates under well-defined circumstances between donor and acceptor entity, and results in a decreased electron density on the central atom in question. This chemistry is described in greater detail in Chapter 10.

In contrast to most organometallic catalysts - which achieve catalytic activity via a single (usually Lewis acid) function [52] - most of the currently used efficient organocatalysts have more than one active center. The vast majority of these catalysts are bifunctional catalysts, having commonly a Brønsted acid and Lewis base center [17]. Such catalysts are able to activate both the donor and acceptor, respectively, and this results not only in a considerable acceleration in reaction rate but also in increased selectivity due to the highly organized transition state (TS). Moreover, the fact that the reaction occurs in a confined reaction space means that the catalyst functions as an "entropy trap", in the sense originally proposed by Westheimer ("... by overcoming the unfavorable entropy of activation usually inherent in a chemical reaction.") [53]. In the transition states, hydrogen bond interactions constitute a major driving force in the formation of specific molecular and complex geometries. Thus, protein and nucleic acid secondary and tertiary structural elements - as well as many natural and artificial host-guest complexes - are partly based on the directive power of intra- and intermolecular hydrogen bond formation [54]. It should be noted that Brønsted acids may also participate actively in the chemical transformation; indeed, in many cases the chiral proton transfer determines both the rate and selectivity of the global process.

Although the first catalysts to be identified were naturally occurring molecules having a rigid backbone, organocatalytic reactions have essentially evolved from the ligand chemistry of organometallic reactions. Today, the large array of ligands developed for metal-mediated reactions are still among the best-performing organocatalysts. Paradoxically, these ligands were considered originally exclusively to be chiral manifolds, without realizing the benefits of the presence of the catalytically active functionalities. The main advantages of synthetic molecules over their natural counterparts are their readily available enantiomers and easily tunable structures. Moreover, compound classes having no naturally occurring analogues can also be obtained. While there is no naturally occurring source of phosphoruscontaining chiral compounds for catalytic use, there is understandably an intense synthetic activity to close the gap, and in this respect there are two complementary strategies for catalyst development:

- variation of the structure of an efficient catalyst family, usually that of a privileged class [55]; and

- the generation and testing of a large number of catalysts (library), and selection of the one(s) having the best kinetic/selectivity profile. 
The massive involvement of automatization and computation, both in the generation of novel catalyst structures and in the evaluation of the reactions, facilitates the emergence of new catalyst structures. This approach is particularly useful when preparing peptide-based catalysts, which fold into defined secondary structures in either organic or aqueous solution. The "oligopeptide approach" has some advantages. First, the efficiency of the catalyst can be improved by varying the nature of the amino acids using combinatorial synthetic methods. Second, the structural simplicity of the oligopeptides contrasts with the complexity of the enzymes and thus renders easier the mechanistic investigations. Third, the flexibility of the method is of great use. It is possible to prepare a peptide sequence that can produce, eventually, the opposite enantiomer or its diastereoisomer, a process barely amenable with enzymes. Moreover, this oligopeptide approach may provide the solution for the reactivity versus selectivity problem, notably when the steric hindrance of the chiral appendage compromises the reactivity of the catalyst. Here, the strategy consists of building a simplified version of a complex chiral environment around the catalytic site, very much like that found in enzymes, where the chiral handle is thus distant from the active site. Such artificial enzymes may comprise a short oligopeptide sequence that includes an active site (e.g., imidazole), and a basic secondary structure, for example an $\alpha / \beta$-turn or $\alpha / \beta$-hairpin. It is interesting to contemplate, that with the spectacular increase in molecular weight and complexity of many catalyst structures, it is not only the selectivity but also the kinetic profile of the catalyst that is sharply ameliorated.

\subsection{1}

\section{Privileged Catalysts}

Some catalysts may have the extraordinary capacity to mediate efficiently not only one but rather a variety of seemingly unrelated chemical transformations. The term "privileged" chiral catalysts was coined in analogy to pharmaceutical compound classes that are active against a number of different biological targets [55]. Indeed, there is a steadily growing number of such organic compounds included in this list, the details for some of which are outlined in the following sections.

\subsubsection{Proline [7k, 56]}

L-Proline is perhaps the most well-known organocatalyst. Although the natural L-form is normally used, proline is available in both enantiomeric forms [57], this being somewhat of an asset when compared to enzymatic catalysis [58]. Proline is the only natural amino acid to exhibit genuine secondary amine functionality; thus, the nitrogen atom has a higher $\mathrm{p} K_{\mathrm{a}}$ than other amino acids and so features an enhanced nucleophilicity compared to the other amino acids. Hence, proline is able to act as a nucleophile, in particular with carbonyl compounds or Michael acceptors, to form either an iminium ion or enamine. In these reactions, the carboxylic function of the amino acid acts as a Brønsted acid, rendering the proline a bifunctional catalyst. 
The high, and often exceptional, enantioselectivity of proline-mediated reactions can be rationalized by the capacity of the molecule to orchestrate highly organized transition states by an extensive hydrogen-bonding network. In all proline-mediated reactions, proton-transfer from the amine or the carboxylic acid group of proline to the forming alkoxide or imide is essential for charge stabilization and to facilitate $\mathrm{C}-\mathrm{C}$ bond formation in the transition state [59]. While most of the partial steps in aminocatalytic reactions are in equilibrium, the enhanced nucleophilicity of the catalyst can entail a number of equilibrated reactions with electrophiles present in the medium, resulting in a low turnover number. However, this drawback can be remedied by upsetting the equilibrium by higher catalyst loading, whilst the catalyst is of low cost.

Synthetic shortcomings related to proline are persistent, however. For example, in the dimerization or oligomerization of $\alpha$-unbranched aldehydes, it is difficult to avoid competing reactions. Reactions with acetaldehyde or acetophenone afford generally low yields and selectivity in aldol reactions. Although proline continues to play a central role in aminocatalysis, its supremacy is being challenged either by new synthetic analogues [60], or by more complex oligopeptides. Structural analogues or derivatives offer better rates and selectivity in a number of reactions.

\subsubsection{Cinchona Alkaloids [61]}

The readily available and inexpensive cinchona alkaloids having pseudoenantiomeric forms such as quinine and quinidine, or cinchonine and cinchonidine, are among the most efficient catalysts (Scheme 1.7). The key structural feature responsible for their synthetic utility is the presence of the tertiary quinuclidine nitrogen, which complements with the proximal polar hydroxyl function of the natural compound. The presence of these Lewis acidic (H-bonding) and Lewis basic (quinuclidine nitrogen) sites makes them bifunctionally catalytic. The range

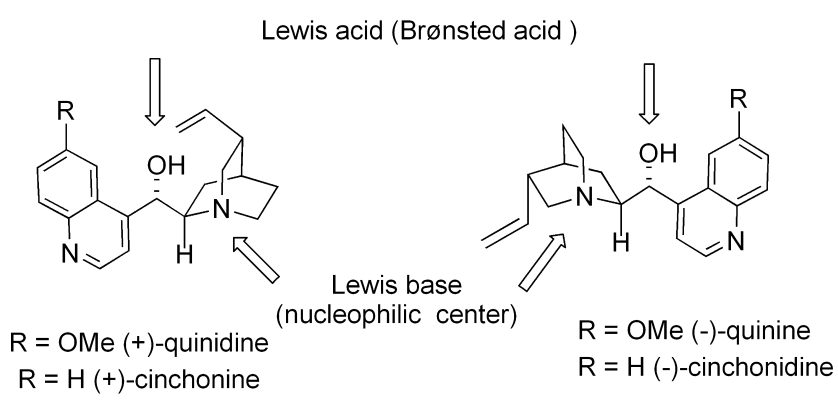

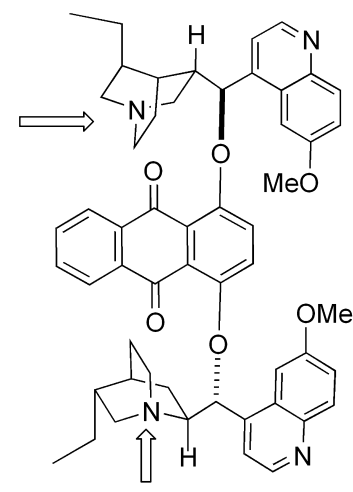

Lewis base can play as Lewis acid if protonated

Scheme 1.7 Some cinchona alkaloids and cinchona-derived catalysts. 
of reaction types over which the cinchona alkaloids impart high enantioselectivity is astonishing. In the past, modification of the cinchona backbone has resulted in notorious decreases or even losses of selectivity, and consequently such derivatives were disregarded as catalysts. The major event causing modified cinchonas to become the center of attention was the development of dimeric cinchona alkaloid ligands for the asymmetric dihydroxylation of simple olefins [62]. In fact, a very large number and variety of derivatives offer very high levels of selectivity over a wide diversity of reactions.

\subsubsection{TADDOL and Derivatives [63]}

TADDOL is one of the oldest, and most extraordinarily versatile, chiral auxiliaries (Scheme 1.8). The initial design of TADDOL was driven by practical considerations, mainly because it is derived from tartaric acid - the least-expensive chiral starting material with twofold symmetry available from natural sources. The two hydroxyl functions of the genuine molecule can act as a double hydrogen-bond donor, allowing the formation of bidentate complexes. Moreover, these functions can be easily substituted, giving access to a variety of derivatives.<smiles>CC1(C)OC([C@H](O)c2ccccc2)C(C(O)(c2ccccc2)c2ccccc2)O1</smiles>

TADDOL

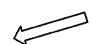<smiles>[C]=C</smiles>

Lewis acid<smiles>[X]c1ccc2ccccc2c1-c1c([X])ccc2ccccc12</smiles><smiles>C=C</smiles>
$\mathrm{X}=\mathrm{OH} \quad$ Lewis acid $\mathrm{X}=\mathrm{PPh}_{2}$ Lewis base

Scheme 1.8 Taddol and binaphthol-derived catalysts.

\subsubsection{Binaphthol Derivatives}

The enantiomeric atropoisomers of $1,1^{\prime}$-binaphthyl-2,2'-diol (BINOL) and bisdiphenylphosphonate derivatives (BINAP) are completely synthetic molecules that have been developed to exploit the axial dissymmetry induced by the restricted rotation about the biaryl bond (Scheme 1.8) [64]. During the past 15 years, these compounds have become the most widely used ligands for both stoichiometric and catalytic asymmetric reactions, with many analogues and derivatives having been developed recently.

\section{4}

\section{Reaction Types}

Normally, organocatalytic reactions proceed either by a much "tighter" or a much "looser" transition structure than chiral metal complex-mediated reactions. The 
former class involves compounds, which are acting as covalently (truly) bonded reagents, with the bonding energy between catalyst and substrate exceeding $15 \mathrm{kcal}$. The latter class includes reactions via non-covalent complexes, and usually via ion pairing as dominant interactions, and encompasses interactions lower than $4 \mathrm{kcal} \mathrm{mol}^{-1}[4]$.

\subsection{1}

\section{Covalent Catalysis}

The vast majority of organocatalytic reactions proceeds via covalent formation of the catalyst-substrate adduct to form an activated complex. Amine-based reactions are typical examples, in which amino acids, peptides, alkaloids and synthetic nitrogen-containing molecules are used as chiral catalysts. The main body of reactions includes reactions of the so-called generalized enamine cycle and charge accelerated reactions via the formation of iminium intermediates (see Chapters 2 and 3). Also, Morita-Baylis-Hillman reactions (see Chapter 5), carbene-mediated reactions (see Chapter 9), as well as asymmetric ylide reactions including epoxidation, cyclopropanation, and aziridination (see Chapter 10), and oxidation with the in situ generation of chiral dioxirane or oxaziridine catalysts (see Chapter 12), are typical examples.

\section{4 .2}

\section{Non-Covalent Organocatalysis}

There are a growing number of asymmetric organocatalytic reactions, which are accelerated by weak interactions. This type of catalysis includes neutral hostguest complexation, or acid-base associations between catalyst and substrate. The former case is highly reminiscent of the way that many enzymes effect reactions, by bringing together reactants at an active site and without the formation of covalent bonds. The chemistry of this organocatalysis is discussed in Chapter 13.

Weak acid-base chiral complex formation represents hydrogen bond catalysis (see Chapter 9) and deprotonation followed by cation/anion association under homogeneous, and also under phase-transfer conditions (see Chapter 4) [14, 65].

\section{5}

\section{How This Book is Organized}

The goal of this handbook is to bring together all important aspects of the rapidly growing field of asymmetric organocatalysis. The authors have attempted this difficult task in order to provide some practical guidelines for all of those who wish to familiarize themselves with this new domain, and also to provide useful information to those who are contributing actively to the extraordinary evolution of this field. The book is divided into two complementary parts: 
- "Reactions" (Chapters 2 to 13), which discuss the most currently used organocatalytic transformations and provide a scholar mechanism-based treatment of the major reaction types.

- "Experimental Procedures" (Chapter 14), which gathers critically selected howto-do-it protocols, classified according to transformation types.

\section{References and Notes}

1 Metalloids are usually included, as non-metallic elements. This book will consider arbitrarily $\mathrm{Si}$ and discard B.

2 The exclusion of metal elements from the catalyst structure is not always strictly considered. Catalysts where the metal arguably is not the reaction center ("spectator") such as in metallocenes are discussed, under certain conditions. For an excellent review of this chemistry see: G.C. Fu, Acc. Chem. Res. 2006, 34, 853-860.

3 A. Berkessel, H. Gröger, Asymmetric Organocatalysis, From Biomimetic Concepts to Applications in Asymmetric Synthesis. VCH, Weinheim, 2005.

4 General reviews on asymmetric organocatalysis: (a) P.I. Dalko, L. Moisan, Angew. Chem. Sonderausgabe 2005, A147-A184; (b) Y. Hayashi, J. Synth. Org. Chem. Jpn. 2005, 63, 464-477; (c) P.I. Dalko, L. Moisan, Angew. Chem., Int. Ed. 2004, 43, 5138-5175; (d) H.F. Jiang, Y.G. Wang, H.L. Liu, et al. Chin. J. Org. Chem. 2004, 24, 1513-1531; (e) P.I. Dalko, in: The McGraw-Hill 2003 Yearbook. McGraw-Hill, New York, 2003, pp. 312-315; (f) P.I. Dalko, L. Moisan, Angew. Chem. Int. Ed. Engl. 2001, 40, 3726-3748.

5 Special issues on asymmetric organocatalysis. B. List, C. Bolm (Eds.), Adv. Synth. Catal. 2004, 346, 1007-1249; K.N. Houk, B. List (Eds.), Acc. Chem. Res. 2004, 37 (8).

6 Reviews on organometallic/ organocatalytic interface: (a) B. Plietker, Angew. Chem. Int. Ed. 2006, 45, 190-192; (b) P. Kočovský, A.V.
Malkov, Russ. Chem. Bull. 2004, 53, 1806-1812.

7 Reviews on aminocatalysis: (a) B. List, Chem. Commun., 2006, 819-824; (b) G. Lelais, D.W.C. MacMillan, Aldrichimica Acta, 2006, 39, 79-87; (c) M. Marigo, K.A. Jørgensen, Chem. Commun. 2006, 2001-2011; (d) J. Seayad, B. List, Org. Biomol. Chem. 2005, 3, 719-724; (e) A.J.A. Cobb, D.M. Shaw, D.A. Longbottom, J.B. Gold, S.V. Ley, Org. Biomol. Chem. 2005, 3, 84-96; (f) X.F. Wei, Chin. J. Org. Chem. 2005, 25, 1619-1625; (g) S.B. Tsogoeva, Lett. Org. Chem. 2005, 2, 208-213; (h) B. List, Acc. Chem. Res., 2004, 37, 548-557; (i) S. France, D.J. Guerin, S.J. Miller, T. Lectka, Chem. Rev. 2003, 103, 2985-3012; (j) B. List, Tetrahedron 2002, 58, 55725590; (k) M. Movassaghi, E.N. Jacobsen, Science 2002, 298, 1904; (1) E.R. Jarvo, S.J. Miller, Tetrahedron 2002, 58, 2481-2495; (m) H. Gröger, J. Wilken, Angew. Chem. Int. Ed. Engl. 2001, 40, 529-532; (i) B. List, Synlett, 2001, 1675-1686. See also Ref. [61].

8 Morita-Baylis-Hillman reactions: (a) K.Y. Lee, S. Gowrisankar, J.N. Kim, Bull. Korean Chem. Soc. 2005, 26, 1481-1490; (b) D. Basavaiah, A.J. Rao, T. Satyanarayana, Chem Rev. 2003, 103, 811-891; (c) P. Langer, Angew. Chem. Int. Ed. 2000, 39, 3049-3052.

9 Reviews on asymmetric catalysis by chiral hydrogen-bond donors: (a) T. Akiyama, J. Itoh, K. Fuchibe, Adv. Synth. Catal. 2006, 348, 999-1010; (b) M.S. Taylor, E.N. Jacobsen, Angew. Chem. Int. Ed. 2006, 45, 1520-1543; 
(c) C. Bolm, T. Rantanen, I. Schiffers, L. Zani, Angew. Chem. Int. Ed. 2005, 44, 1758-1763; (d) H. Yamamoto, K. Futatsugi, Angew. Chem. Int. Ed. 2005, 44, 1924-1942; (e) C.A. Hunter, Angew. Chem. Int. Ed. 2004, 43, 53105324; (f) P.M. Pihko, Angew. Chem. Int. Ed. 2004, 43, 2062-2064; (g) M. Oestreich, Nachr. Chem. 2004, 52, 3538; (h) P.R. Schreiner, Chem. Soc. Rev. 2003, 32, 289-296; (i) S.J. Connon, Chem. Eur. J. 2006, 12, 5418-5427.

10 Reviews on asymmetric acylation: (a) E. Vedejs, M. Jure, Angew. Chem. Int. Ed. 2005, 44, 3974-4001; (b) D.E.J.E. Robinson, S.D. Bull, Tetrahedron: Asymm. 2003, 14, 1407-1446; (c) J.R. Dehli, V. Gotor, Chem. Soc. Rev. 2002, 31, 365-370; (d) F.F. Huerta, A.B.E. Minidis, J.-E. Bäckvall, Chem. Soc. Rev. 2001, 30, 321-331; (e) J. Eames, Angew. Chem. Int. Ed. 2000, 39, 885888.

11 Reviews on asymmetric reactions via carbenes: D. Enders, T. Balensiefer, Acc. Chem. Res. 2004, 37, 534-541.

12 Reviews on asymmetric oxidation reactions: (a) A.K. Yudin, Aziridines and Epoxides in Organic Synthesis, Wiley-VCH, Weinheim, 2006; (b) E.M. McGarrigle, D.G. Gilheany, Chem. Rev. 2005, 105, 1563-1602; (c) Q.-H. Xia, H.-Q. Ge, C.-P. Ye, Z.-M. Liu, K.-X. Su, Chem. Rev. 2005, 105 , 1603-1662; (d) Y. Shi, Acc. Chem. Res. 2004, 37, 488-496; (e) D. Yang, Acc. Chem. Res. 2004, 37, 497-505;

(f) W. Adam, C.R. Saha-Moller, P.A. Ganeshpure, Chem. Rev. 2001, 101, 3499-3548.

13 Reviews on Lewis base-catalyzed transformations: (a) S.E. Denmark, J. Fu, Chem. Commun. 2003, 167; (b) S.E. Denmark, J. Fu, Chem. Rev. 2003, 103, 2763; (c) J.W.J. Kennedy, D.G. Hall, Angew. Chem., Int. Ed. 2003, 42, 4732; (d) S.E. Denmark, R.A. Stavenger, Acc. Chem. Res. 2000, 33, 432.

14 Reviews on asymmetric phasetransfer reactions: (a) B. Lygo, B.I. Andrews, Acc. Chem. Res. 2004, 37, 518-525; (b) K. Maruoka, T. Ooi,
Chem. Rev. 2003, 103, 3013-3028; (c) C. Najera, Synlett 2002, 1388-1403; (d) M.J. O'Donnell, Aldrichimica Acta 2001, 34, 3-15.

15 Reviews on asymmetric shape and site selective organocatalytic reactions:

(a) R. Breslow (Ed.), Artificial Enzymes, Wiley-VCH, Weinheim, 2005; (b) C.W. Lim, B.J. Ravoo, D.N. Reinhoudt, Chem. Commun. 2005, 5627-5629; (c) C. Alexander, L. Davidson, W. Hayes, Tetrahedron 2003, 59, 2025-2056; (d) G. Wulff, Chem. Rev. 2002, 102, 1-28; (e) B. Clapham, T.S. Reger, K.D. Janda, Tetrahedron 2001, 57, 4637-4662; (f) B. Sellergren, Angew. Chem. Int. Ed. 2000, 39, 1031-1037.

16 (a) J. Seayad, B. List, Catalytic asymmetric multi-component reactions. In: J. Zhu, H. Bienayme (Eds.), Multi-Component Reactions. Wiley-VCH: Weinheim, Germany, 2004; (b) D.B. Ramachary, M. Kishor, G.B. Reddy, Org. Biomol. Chem. 2006, 4, 1641-1646; (c) H.-C. Guo, J.-A. Ma, Angew. Chem. Int. Ed. 2006, 45, 354366.

17 (a) H. Bernard, G. Bulow, U.E.W. Lange, H. Mack, T. Pfeiffer, B. Schäfer, W. Seitz, T. Zierke, Synthesis 2004, 2367-2375; (b) M. Breuer, K. Ditrich, T. Habicher, B. Hauer, M. Kesseler, R. Sturmer, T. Zelinski, Angew. Chem. Int. Ed. 2004, 43, 788824; (c) H. Tye, P.J. Comina, J. Chem. Soc., Perkin 1 2001, 1729-1747; (d) H.J. Federsel, Nature Rev. Drug Discov. 2005, 4, 685-697; (e) H.U. Blaser, B. Pugin, F. Spindler, J. Mol. Catal., Chemical 2005, 231, 1-20.

18 C. Thirsk, D. Jay, Chem. Ind. 2004, 16, 15-17.

19 S. Pizzarello, A.L. Weber, Science 2004, 303, 1151.

20 G.M.M. Caro, U.J. Meierhenrich, W.A. Schutte, B. Barbier, A.A. Segovia, H. Rosenbauer, W.H.-P. Thiemann, A. Brack, J.M. Greenberg, Nature 2002, 416, 403.

21 (a) M. Klussmann, H. Iwamura, S.P. Mathew, D.H. Wells, Jr., U. Pandya, A. Armstrong, D.G. Blackmond, 
Nature 2006, 441, 621; (b) Y. Hayashi, M. Matsuzawa, J. Yamaguchi, S. Yonehara, Y. Matsumoto, M. Shoji, D. Hashizume, H. Koshino, Angew. Chem. Int. Ed. 2006, 45, 4593-4597; (c) A.B. Northrup, D.W.C. MacMillan, Science 2005, 305, 1752; (d) A. Córdova, M. Engqvist, I. Ibrahem, J. Casas, H. Sunden, Cheminform, 2005, 36, (32); (e) A. Córdova, I. Ibrahem, J. Casas, H. Sundén, M. Engqvist, E. Reyes, Chem. Eur. J. 2005, 11, 47724784; (f) A. Córdova, M. Engqvist, I. Ibrahem, J. Casas, H. Sundén, Chem. Commun. 2005, 2047-2049; (g) U. Kazmaier, Angew. Chem. Int. Ed. 2005, 44, 2186-2188. (h) See also: G. Carrea, S. Colonna, D.R. Kelly, A. Lazcano, G. Ottolina, S.M. Roberts, Trends Biotechnol. 2005, 23, 507-513.

22 (a) G.F. Joyce, G.M. Visser, C.A.A. van Boeckel, J.H. van Boom, L.E. Orgel, J. van Westerenen, Nature 1984, 310, 602-604; (b) M. Bolli, R. Micura, A. Eschenmoser, Chem. Biol. 1997, 4, 309-320.

23 K. Tamura, P. Schimmel, Science 2004, 305, 1253.

24 H.B. Kagan. In: E.N. Jacobsen, A. Pfaltz, H. Yamamoto (Eds.), Comprehensive Asymmetric Catalysis, Springer-Verlag, Berlin, 1999, Vol. 1, pp. 101-118.

25 G. Breding, R.W. Balcom, Ber. Deutsch. Chem. Ger. 1908, 41, 740-751.

26 G. Breding, K. Fajans, Ber. Deutsch. Chem. Ger. 1908, 41, 752-763.

27 L. Rosentahler, Biochem. Z. 1908, 14, 232.

28 G. Breding, P.S. Fiske, Biochem. Z. 1912, 46, 7.

29 M.M. Vavon, P. Peignier, Bull Soc. Fr. 1929, 45, 293.

30 R. Wegler, Liebigs Ann. Chem. 1932, 498, 62.

31 See W. Langenbeck, Die Organische Katalysatoren und ihre Beziehungen zu den Fermenten 2. Aufl. SpringerVerlag, 1949; (b) W. Langenbeck, Fortschritte der Chemischen Forschung, Vol. 6, Springer Verlag, Berlin, p. 301, 1966; see also in (c)
B. Lukowczyk, J. Pract. Chem 1959, 8, 372-378.

32 H.D. Dakin, J. Biol. Chem. 1909, 7, 49.

33 V. Prelog, M. Wilhelm, Helv. Chim. Acta, 1954, 37, 1634.

34 H. Pracejus, Justus Liebigs Ann. Chem. 1960, 634, 9-22.

35 B. Långström, G. Bergson, Acta Chem. Scand. 1973, 27, 3118-3119.

36 For a review, see: H. Wynberg, Top. Stereochem. 1986, 16, 87-129.

37 Z.G. Hajos, D.R. Parrish, J. Org. Chem. 1974, 39, 1615-1621.

38 U. Eder, G. Sauer, R. Wiechert, Angew. Chem. Int. Ed. Engl. 1971, 10, 496-497.

39 See for example: S.J. Danishefsky, J.J. Masters, W.B. Young, J.T. Link, L.B. Snyder, T.V. Magee, D.K. Jung, R.C.A. Isaacs, W.G. Bornmann, C.A. Alaimo, C.A. Coburn, M.J. Di Grandi, J. Am. Chem. Soc. 1996, 118, 2843-2859.

40 G. Stork, R. Terrell, J. Szmuszkovicz, J. Am. Chem. Soc. 1954, 76, 20292030.

41 For a pioneering review dealing with proline as catalyst, see: J. Martens, Top. Curr. Chem. 1984, 125, 165-246.

42 T.P. Brady, S.H. Kim, K. Wen, E.A. Theodorakis, Angew. Chem. 2004, 116, 757-760; Angew. Chem. Int. Ed. 2004, 43, 739-742 and references cited therein.

43 A. Mori, S. Inoue. In: E.N. Jacobsen, A. Pfalz, H. Yamamoto (Eds.), Comprehensive Asymmetric Catalysis. Springer, Heidelberg, 1999, pp. 983994 and references therein.

44 M.S. Iyer, K.M. Gigstad, N.D. Namdev, M. Lipton, J. Am. Chem. Soc. 1996, 118, 4910-4911.

45 M.S. Sigman, E.N. Jacobsen, J. Am. Chem. Soc. 1998, 120, 4901-4902.

46 (a) U.-H. Dolling, P. Davis, E.J.J. Grabowski, J. Am. Chem. Soc. 1987, 106, 446-447; (b) D.L. Hughes, U.-H. Dolling, K.M. Ryan, E.F. Schoenewaldt, E.J.J. Grabowski, J. Org. Chem. 1987, 52, 4745-4752. 
47 For a review on catalytic Diels-Alder reactions, see: (a) H.B. Kagan, O. Riant, Chem. Rev. 1992, 92, 1007-1019.

48 (a) S. Juliá, J. Masana, J.C. Vega, Angew. Chem. Int. Ed. 1980, 19, 929931; (b) S. Juliá, J. Guixer, J. Masana, J. Rocas, S. Colonna, R. Annuziata, H. Molinari, J. Chem. Soc., Perkin Trans. 1 1982, 1317. For a mechanistic discussion of this reaction, see: (c) A. Berkessel, N. Gasch, K. Glaubitz, C. Koch, Org. Lett. 2001, 3, 3839-3842.

49 For a review on phosphines, see: J.L. Methot, W.R. Roush, Adv. Synth. Catal. 2004, 346, 1035-1050.

50 As defined in Ref. [7i]: "There are two aminocatalytic pathways. Iminium catalysis directly utilizes the higher reactivity of the iminium ion in comparison to the carbonyl species and facilitates Knoevenagel-type condensations, cyclo- and nucleophilic additions, and cleavage of $\sigma$-bonds adjacent to the $\alpha$-carbon. Enamine catalysis on the other hand involves catalytically generated enamine intermediates that are formed via deprotonation of an iminium ion, and react with various electrophiles or undergo pericyclic reactions."

51 (a) J.W. Yang, M.T. Hechavarria Fonseca, B. List, J. Am. Chem. Soc. 2005, 127, 15036-15037; (b) Y. Huang, A. Walji, C.H. Larsen, D.W.C. MacMillan, J. Am. Chem. Soc. 2005, 127, 15051-15053.

52 For reviews on bifunctional catalysts:

(a) M. Shibasaki, H. Sasai, T. Arai, Angew. Chem. Int. Ed. Engl. 1997, 36, 1236-1256; (b) H. Gröger, Chem. Eur. J. 2001, 7, 5246-5251; (c) G.J. Rawlands, Tetrahedron 2001, 57, 1865-1882; (d) M. Shibasaki, N. Yoshikawa, Chem. Rev. 2002, 102, 2187-2209; (e) J.-A. Ma, D. Cahard, Angew. Chem. Int. Ed. 2004, 43, 45664583; (f) M. Kanai, N. Kato, E. Ichikawa, M. Shibasaki, Synlett 2005, 10, 1491-1508.

53 (a) F.H. Westheimer, Adv. Enzymol. 1962, 24, 441-482; (b) F.H.
Westheimer, Adv. Phys. Org. Chem. 1985, 21, 1-35.

54 (a) G.A. Jeffrey, W. Saenger, Hydrogen Bonding in Biological Structures. Springer, Berlin, 1994; (b) D.G. Lonergan, G. Deslongchamps, S. Tomás, Tetrahedron Lett. 1998, 39, 7861-7864.

55 T.P. Yoon, E.N. Jacobsen, Science 2003, 299, 1691-1693.

56 W.D. Allen, E. Czinki, A.G. Csaszar, Chem. Eur. J. 2004, 10, 4512-4517.

57 The natural compound is extracted essentially from chicken feathers.

58 J. Sukumaran, U. Hanefeld, Chem. Soc. Rev. 2005, 34, 530-542.

59 (a) S. Bahmanyar, K.N. Houk, Org. Lett. 2003, 5, 1249-1251; (b) S. Bahmanyar, K.N. Houk, H.J. Martin, B. List, J. Am. Chem. Soc. 2003, 125 , 2475-2479; (c) L. Hoang, S. Bahmanyar, K.N. Houk, B. List, J. Am. Chem. Soc. 2003, 125, 16-17; (d) S. Bahmanyar, K.N. Houk, J. Am. Chem. Soc. 2001, 123, 12911-12912; (e) S. Bahmanyar, K.N. Houk, J. Am. Chem. Soc. 2001, 123, 11273-11283.

60 For related derivatives, see: (a) M. Nakadai, S. Saito, H. Yamamoto, Tetrahedron 2002, 58, 8167-8177; (b) Z. Tang, F. Jiang, L.-T. Yu, X. Cui, L.-Z. Gong, A.-Q. Mi, Y.-Z. Jiang, Y.-D. Wu, J. Am. Chem. Soc. 2003, 125, 5262-5263; (c) F. Fache, O. Piva, Tetrahedron: Asymmetry 2003, 14, 139-143; (d) T.J. Dickerson, K.D. Janda, J. Am. Chem. Soc. 2002, 124, 3220-3221; (e) A.J.A. Cobb, D.M. Shaw, S.V. Ley, Synlett 2004, 558-560.

61 (a) S.-K. Tian, Y. Chen, J. Hang, L. Tang, P. McDaid, L. Deng, Acc. Chem. Res. 2004, 37, 621-631; (b) C. Ó’Dálaigh, Synlett 2005, 875-876.

62 (a) H.C. Kolb, M.S. VanNieuwenhze, K.B. Sharpless, Chem. Rev. 1994, 94, 2483-2547; (b) I.E. Marko, J.S. Svendsen. In: E.N. Jacobsen, A. Pfaltz, H. Yamamoto (Eds.), Comprehensive Asymmetric Catalysis. Springer, New York, 1999, Vols. I-III, Chapter 20.

63 D. Seebach, A.K. Beck, A. Heckel, Angew. Chem. Int. Ed. Engl. 2001, 40, 92-138. 
64 See for example: (a) M. Shibasaki, S. Matsunaga, Chem. Soc. Rev. 2006, 35, 269-279; (b) J.M. Brunel, Chem. Rev., 2005, 105, 857-898; (c) A.K. Unni, N. Takenaka, H. Yamamoto, V.H. Rawal,
J. Am. Chem. Soc. 2005, 127, 13361337.

65 M. Makosza, M. Fedorynski, Catal. Rev., Sci. Eng. 2003, 45, 321-367. 
